\title{
STRESS INTENSITY FACTOR CALCULATIONS FOR THE COMPRESSOR BLADE WITH HALF-ELLIPTICAL SURFACE CRACK USING RAJU-NEWMAN SOLUTION
}

\author{
Lucjan Witek \\ University of Technology \\ Rzeszów, Poland
}

\begin{abstract}
This paper presents results of the stress intensity factor calculations for the compressor blade including a half-elliptical crack, subjected to vibration. In this analysis, the Raju-Newman empirical solution for stress intensity factor calculations in the rectangular plate with a halfelliptical flaw was used. The bending stress used in the Raju-Newman solution was computed for the real blade using the finite element method. The K-factor values were calculated only at one point of the crack front, where the crack tip contacts the free surface, because the crack length during experimental investigations was measured just in this direction. In order to determine the stress intensity factors for different crack sizes, ten diverse flaws in the blade were defined. Results of the experimental fatigue tests performed for the blade without preliminary defects showed that the cracks developed from the convex blade surface. On the blade fracture, the beach marks typical of the fatigue damage were visible. The dimensions of cracks in the rectangular plate were defined based on the beach marks shape. In the next part of the work, the stress intensity factor values were used as an input data into the Paris-Erdogan equation. As a result of this calculation, the crack growth rate for the compressor blade vibrating at constant amplitude was estimated. The results obtained were finally compared with the results of the experimental crack growth analysis performed for 1st stage compressor blades of the helicopter turbo-engine.
\end{abstract}

\section{INTRODUCTION}

The stress intensity factor is one of the main parameters defined in the fracture mechanics. The stress intensity factor (designated as: SIF, $\mathrm{K}$ or K-factor) has a big influence on the crack growth rate. The $\mathrm{K}$-factor calculation is not easy, especially for geometrically complex structures. In engineering applications, $\mathrm{K}$-factor is often computed numerically using a finite element method (FEM) or a boundary element method (BEM). SIF calculation using FEM is not easy as special degenerated finite elements must be used for the definition of the model zone near the crack tip. The process of element degeneration is usually non-automatic and also very time-consuming.

In 1981 Raju and Newman Jr. published the paper [1] in which the empirical solution for stress intensity factor calculations concerning simple 3D structures was given. In this paper, the solution for the crack intensity factors calculations, for the half-elliptical crack embedded in the compressor blade, was described.

The crack growth analysis of turbine or compressor components has been the focus of several investigations. The crack propagation problem of the high rotational parts used in aviation and also in the power engineering was described by: Barlow et al. [2], Poursaeidi et al. [3], Nikhamkin et 
al. [4] and Troshchenko et al. [5]. The stress intensity factor calculation for the turbine disc with the corner crack using FEM was also described in [6].

The main intention of this work is the stress intensity factor estimation for the compressor blade with a half-elliptical crack based on the Raju-Newman solution. The attention of this paper is also devoted to the crack growth rate determination for the 1st stage compressor blade subjected to vibration at constant amplitude.

\section{COMPRESSOR BLADE DAMAGED IN FATIGUE TEST}

During the stress intensity factor empirical calculations, certain information from the experimental investigations will be used. Thus, the experimental investigations and the object of these investigations should be firstly described.

The 1st stage blade of the PZL-10W turbo-engine (Figs. 1a and 1b) was made from EI-961 austenitic steel $(0.11 \mathrm{C} ; 11 \mathrm{Cr} ; 1.5 \mathrm{Ni}, 1.6 \mathrm{~W} ; 0.18 \mathrm{~V} ; 0.35 \mathrm{Mo} ; 0.025 \mathrm{~S} ; 0.03 \mathrm{P})$ with the following properties (in $20^{\circ} \mathrm{C}$ ) after heat treatment: ultimate tensile strength $900-1090 \mathrm{MPa}$, yield stress 800 $900 \mathrm{MPa}$, Young modulus $200 \mathrm{GPa}$, Poisson ratio 0.3.

The blade during vibration is periodically bent to the left and right side (Fig.1c). Since the cross-section of the blade is non-symmetric, the stress levels under the left and right deflections of blade are different. In the description of the stress analysis results, the information about blade deflection will be placed.

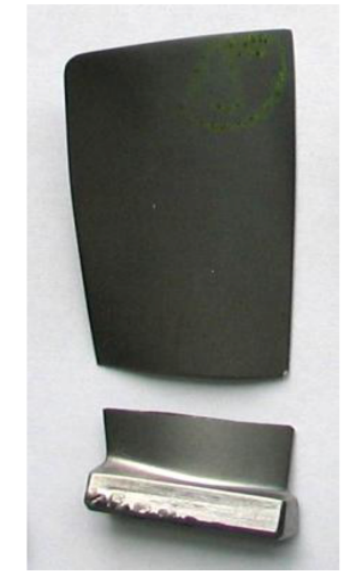

a)

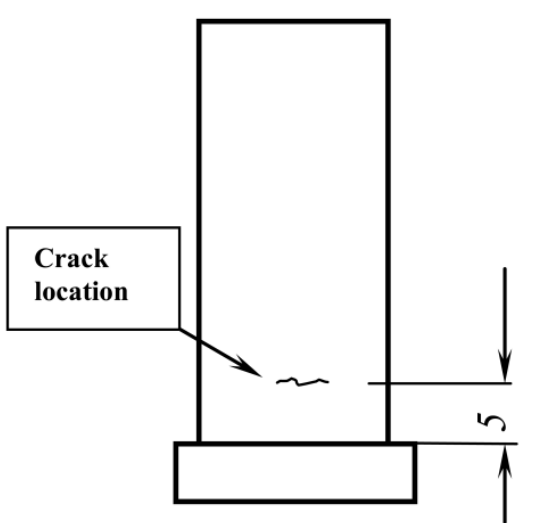

b)

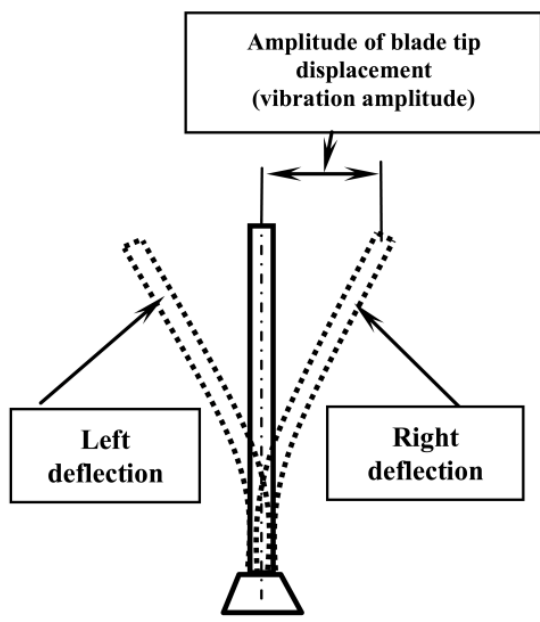

c)

Fig. 1. First stage compressor blade after fatigue test (a), the most frequent crack location in the blade without preliminary defects (b) and the 1st mode of transverse vibrations shape (c)

The fatigue tests performed for the compressor blades were made under the research project No. N N 504 346736, supported by the Polish Ministry of Science and Higher Education. In this project, both non-defected blades and also the ones with preliminary mechanical defects were considered. All experimental investigations were performed at Research and Development Laboratory for Aerospace Materials at the Rzeszów University of Technology. The results of these investigations are shown in Figs. 1a, 2 and 5a. The results of the experimental fatigue tests performed for the blade without preliminary defects are described in work [7].

In Fig. 2 the fatigue fracture of the blade in the preliminary phase of fatigue was shown. Just after the preliminary crack formation, the blade was statically tensioned and ruptured with the use of the testing machine. As seen in Fig. 2, in the blade without mechanical defects or corrosion pits, the crack usually propagates from the convex surface. 


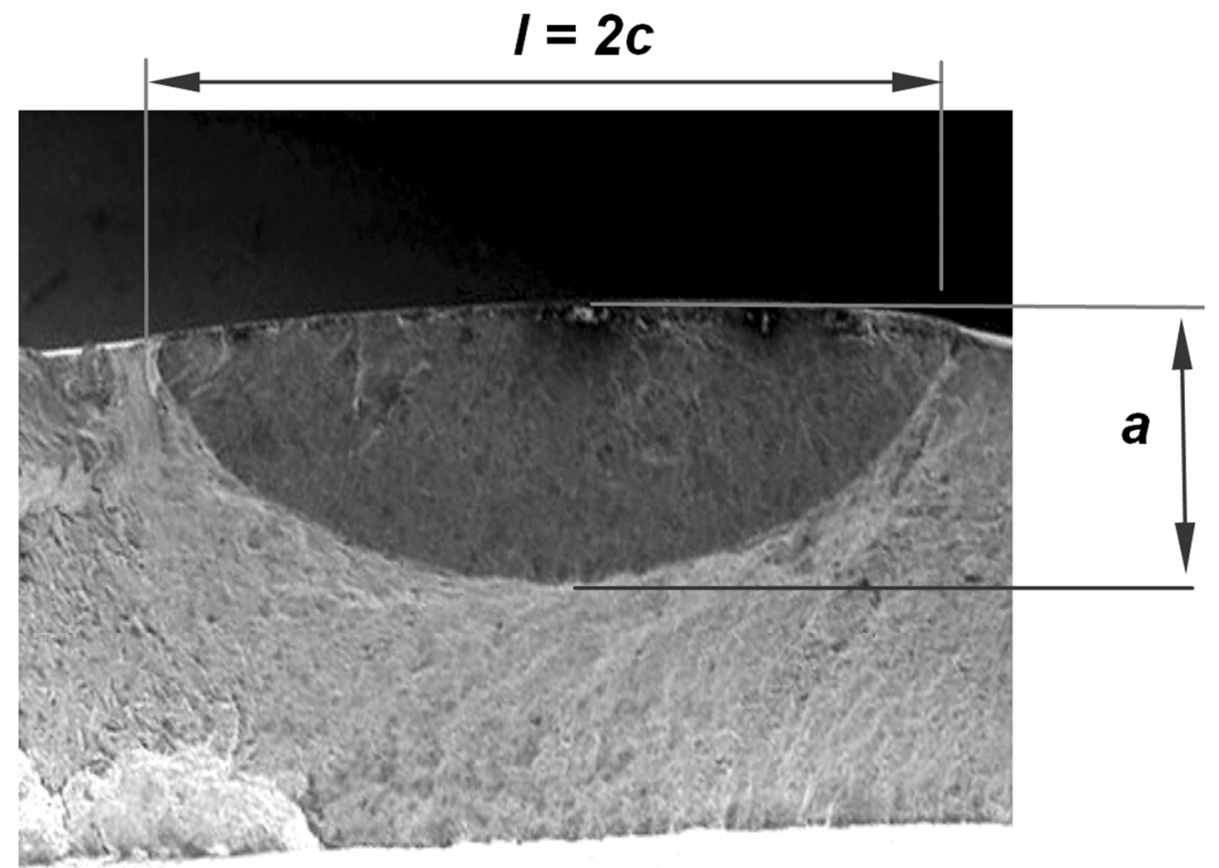

Fig. 2. A half-elliptical crack emanating from the convex blade surface, in the preliminary phase of fracture

\section{RAJU-NEWMAN EMPIRICAL SOLUTION FOR STRESS INTENSITY FACTOR CALCULATIONS FOR SEMI-ELLIPTICAL FLAW IN FLAT PLATE}

In 1981 Raju and Newman Jr. published the paper [1] in which the empirical solutions for stress intensity factor calculations for simple 3D structures were given. According to Raju-Newman, the stress intensity factor $\left(K_{I}\right)$ for the semi-elliptical crack embedded in the flat plate subjected to pure bending (Fig. 3) can be determined by the following equation [1]:

$$
K_{I}=H \times \sigma_{b} \times \sqrt{\frac{\pi \times a}{Q}} \times F\left(\frac{a}{t} ; \frac{a}{c} ; \frac{c}{W} ; \varphi\right)
$$

where:

$\sigma_{\mathrm{b}}$ - bending stress,

a - crack depth (Fig. 3).

The different dimensions used in equation (1) are described in Figs. 3 and 4.

The F function is described by:

$$
F=\left[M_{1}+M_{2}\left(\frac{a}{t}\right)^{2}+M_{3}\left(\frac{a}{t}\right)^{4}\right] f_{\phi} \times f_{w} \times g
$$

where:

$$
M_{1}=1,13-0,09\left(\frac{a}{c}\right)
$$




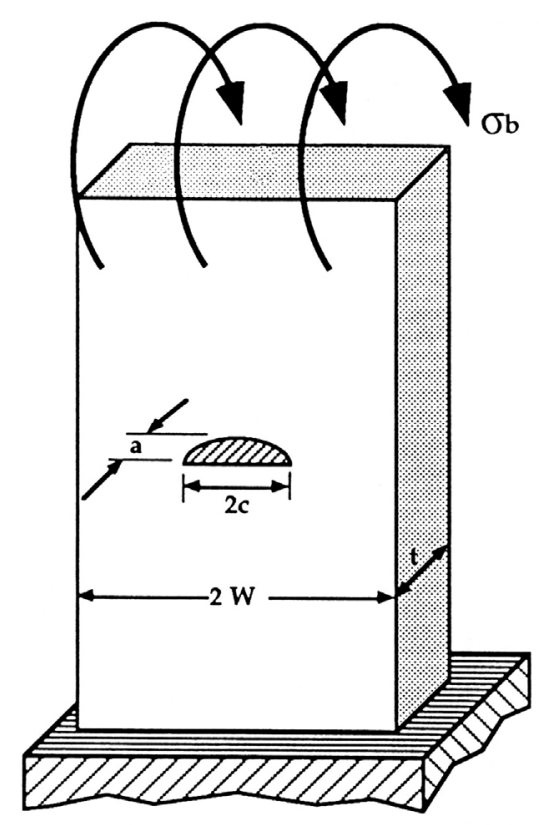

Fig. 3. Semi-elliptical crack embedded in the flat plate subjected to pure bending [1]

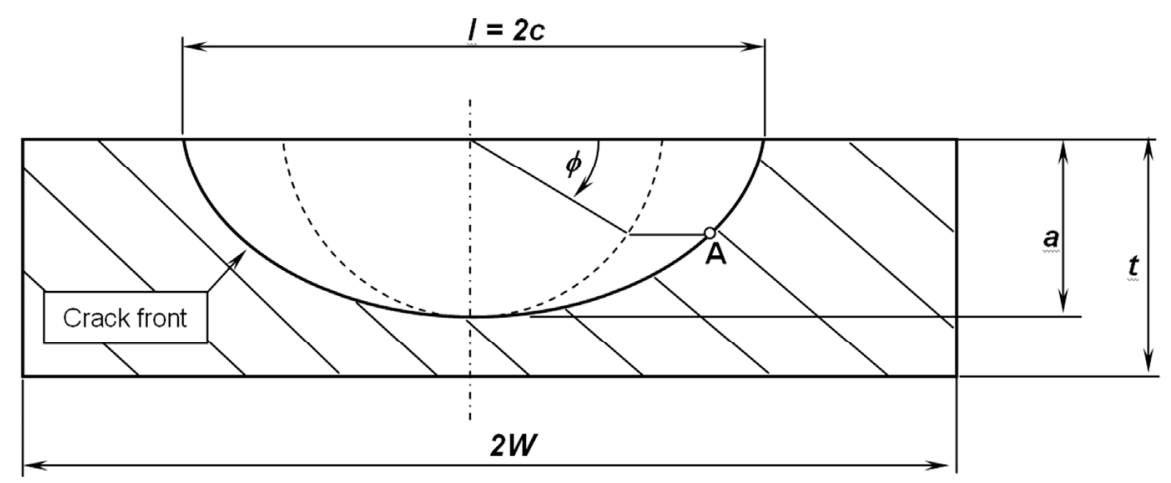

Fig. 4. Location of the point $A$ on the crack front according to Raju-Newman method. Crack and cross-section dimensions [1]

$$
\begin{gathered}
M_{2}=-0,54+\frac{0,89}{0,2+\frac{a}{c}} \\
M_{3}=0,5-\frac{1}{0,65+\frac{a}{c}}+14\left(1-\frac{a}{c}\right)^{24}
\end{gathered}
$$

The $\mathrm{Q}$ function from equation (1) is given by:

$$
Q=1+1,464\left(\frac{a}{c}\right)^{1,65}
$$


The $\mathrm{f}_{\phi}, \mathrm{f}_{\mathrm{w}}$, and $\mathrm{g}$ functions from equation (2) can be expressed as follows:

$$
\begin{gathered}
f_{\varphi}=\left[\left(\frac{a}{c}\right)^{2} \cos ^{2} \phi+\sin ^{2} \varphi\right]^{\frac{1}{4}} \\
f_{w}=\left[\sec \left(\frac{\pi \cdot c}{2 W}\right)^{2} \sqrt{\frac{a}{t}}\right]^{\frac{1}{2}} \\
g=1+\left[0,1+0,35\left(\frac{a}{t}\right)^{2}\right] \cdot(1-\sin \phi)^{2}
\end{gathered}
$$

The $\mathrm{H}$ parameter from equation (1) is given by:

$$
H=H_{1}+\left(H_{2}-H_{1}\right) \cdot(\sin \phi)^{p}
$$

where:

$$
\begin{aligned}
& H_{1}=1-0,34\left(\frac{a}{t}\right)-0,11 \cdot\left(\frac{a}{c}\right) \cdot\left(\frac{a}{t}\right) \\
& H_{2}=1+G_{1}\left(\frac{a}{t}\right)+G_{2}\left(\frac{a}{t}\right)^{2} \\
& G_{1}=-1,22-0,12\left(\frac{a}{c}\right) \\
& G_{2}=0,55-1,05\left(\frac{a}{c}\right)^{0,75}+0,47\left(\frac{a}{c}\right)^{1,5} \\
& p=0,2+\left(\frac{a}{c}\right)+0,6\left(\frac{a}{t}\right)
\end{aligned}
$$

Values of the presented above parameters computed for one point defined on the crack front $(\phi=0)$ will be presented in chapter 5 .

\section{ASSUMPTIONS FOR THE STRESS INTENSITY FACTOR CALCULATIONS IN THE COMPRESSOR BLADE WITH THE USE OF RAJU-NEWMAN SOLUTIONS}

The Raju-Newman solution for the crack in the rectangular plate is defined. The compressor blade cross-section is different from the rectangular shape. The main assumption during the preparation of this work is that the real blade cross-section is replaced with the rectangle. In this case, the Raju-Newman method [1] will be useful for the K-factor estimation in the compressor blade with the half-elliptical crack, emanated from the convex surface. The second assumption is that during the replacement, the rectangular cross-section has the same width $(2 \mathrm{~W})$ and cross- 
section area $\left(36,45 \mathrm{~mm}^{2}\right)$ as the blade. In further analysis, the rectangular cross-section of the blade has the following dimensions: $2 \mathrm{~W}=20,48 \mathrm{~mm}$ (blade chord in the cross-section located 5 $\mathrm{mm}$ above the blade dovetail, Fig. $1 \mathrm{~b}$ ) and $\mathrm{t}=1,78 \mathrm{~mm}$ (Fig. 4).

The blade fracture after fatigue test is presented in Fig. 5a [7]. As seen in this figure, the crack was initiated from the convex surface of the profile, about $6 \mathrm{~mm}$ above the blade locking piece. The crack front shape just after the initiation is close to circular (Fig. 2). In the advanced phase of the fracture, the crack has a semi-elliptical shape (Fig 5a). The fatigue zone covers more than 95\% of the blade fracture. Based on this result, it seems that the stress intensity factor in the advanced phase of the fracture was lower than critical $\left(\mathrm{K}_{\mathrm{IC}}\right)$. The blade presented in Fig. 5a was vibrated with intensity of $12 \mathrm{~g}$ (where $1 \mathrm{~g}$ equals $9,81 \mathrm{~m} / \mathrm{s}^{2}$ ). At this intensity of excitation, the blade tip displacement amplitude after beginning of the fatigue test was about 2,5 $\mathrm{mm}$.

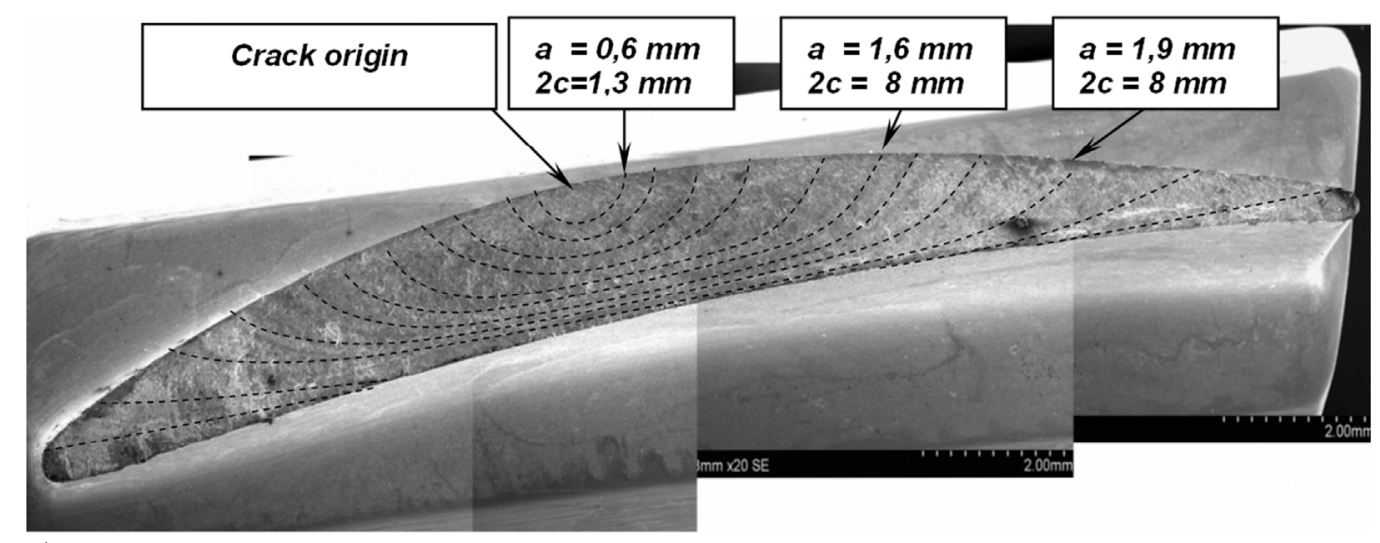

a)

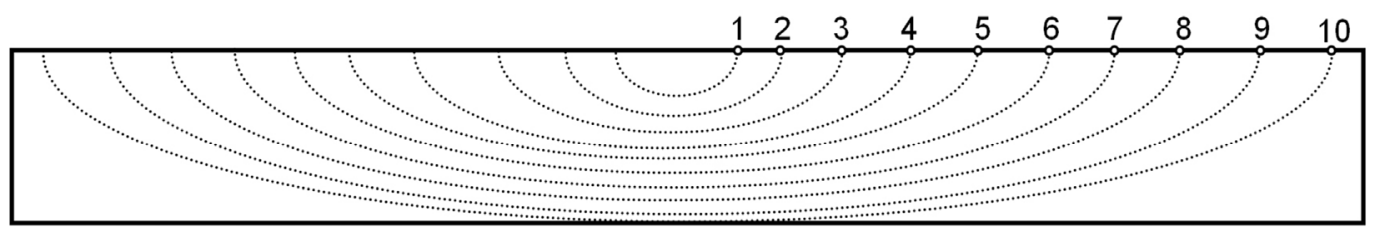

b)

Fig. 5. Fracture of the blade after fatigue test with distinguished selected beach marks [7]

(a) and the replacing rectangular cross-section with the crack fronts defined on the basis of experimental results (b)

In this analysis, ten cracks in the rectangular plate were defined (Fig. 5b). The shape and dimensions of these cracks obtained in experimental fatigue test were determined based on the real beach marks (Fig. 5a). The K-factor will be computed only at points $1 \div 10$ shown in Fig $5 \mathrm{~b}$ (for $\phi=0)$.

The bending stress $\left(\sigma_{\mathrm{b}}\right)$ value is needed to calculate the stress intensity factor with the use of the Raju-Newman equation (1). The value of $\sigma_{\mathrm{b}}$ was taken from results of the FEM numerical calculations performed for the compressor blade which is vibrated with amplitude of $1 \mathrm{~mm}$ (Fig. 6). The maximum value of $\sigma_{z}$ component (bending stress) in the blade cross-section equals 194 $\mathrm{MPa}$. This value was used in stress intensity factor calculations for vibration amplitude of $1 \mathrm{~mm}$. The area of the maximum stress is located on the convex blade surface. The minimum bending stress $(-188 \mathrm{MPa})$ is located near the attack edge of the blade. The maximum value of bending stress is directly proportional to the vibration amplitude. For example, the bending stress for vibration amplitude $\mathrm{A}=2 \mathrm{~mm}$ is computed as $194 \mathrm{MPa}$ multiplied by 2 . 


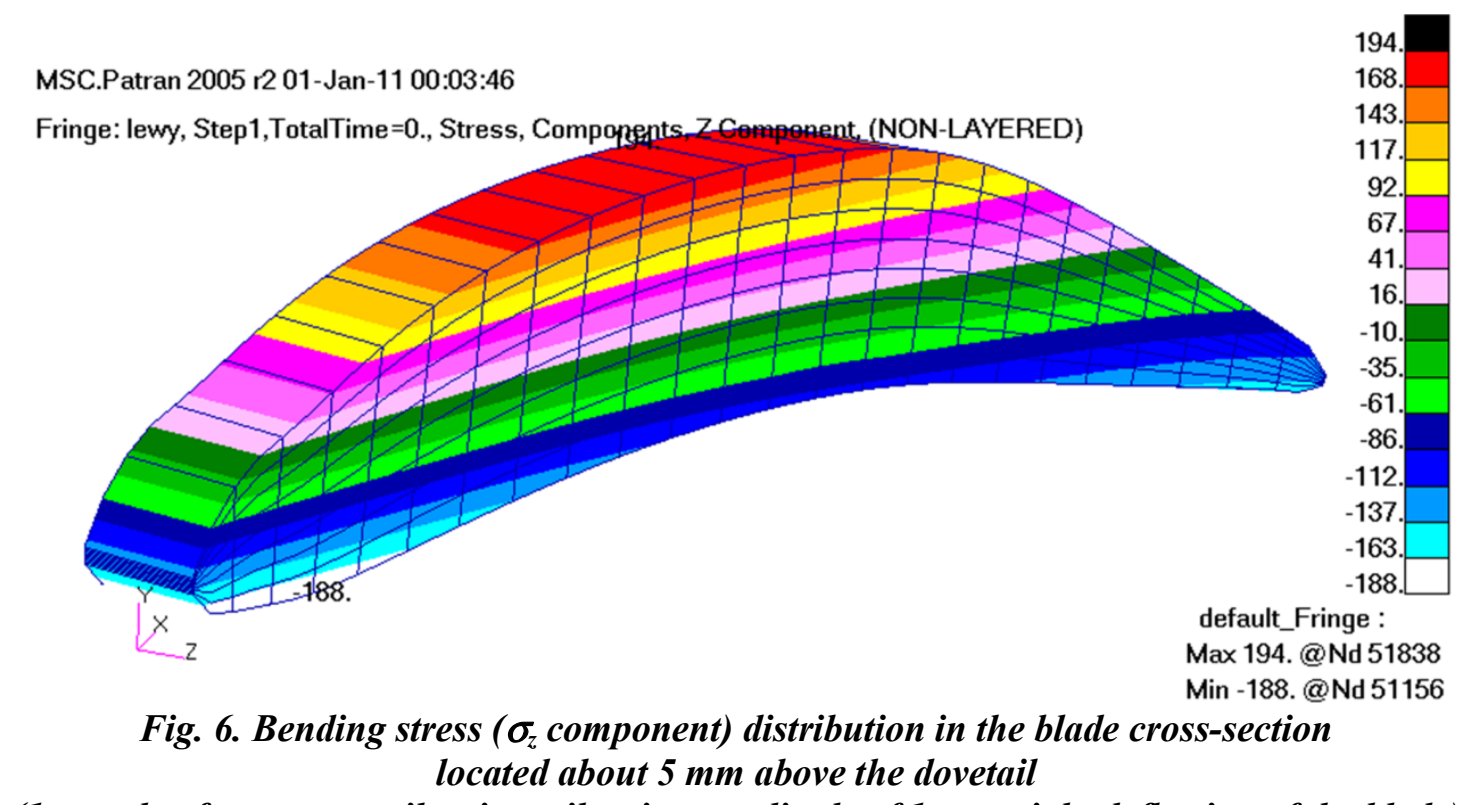

(1st mode of transverse vibration, vibration amplitude of $1 \mathrm{~mm}$, right deflection of the blade)

\section{STRESS INTENSITY FACTOR CALCULATIONS}

The stress intensity factors for only one point on the cracks front were computed. In equations (7, 9 and 10), the $\phi$ value was defined as 0 during calculations. Thus, the K-factor value will be computed only at the beginning (or finishing) point of the crack front, where the crack tip touches the free surface. This direction is distinguished because the crack length (1) was measured just in this direction during experimental crack growth investigations.

Values of the geometrical parameters and also the factors used in the Raju-Newman solution (for $\phi=0$ ) are presented in Tables 1 and 2. Additionally, in Table 2, the values of the stress intensity factors for different crack sizes are shown. The first column of the tables (crack no.) should be associated with the crack numbered in Fig. 5b.

The stress intensity factors, computed for different vibration amplitudes (for $\phi=0$ ) are presented in Fig. 7. As seen in this figure, when the crack has length (1) of about 1,3 mm (crack position no. 1 in Fig. 5b) and is vibrated with amplitude of $1 \mathrm{~mm}$, the stress intensity factor value is about 5 $\mathrm{MPa} \cdot \mathrm{m}^{1 / 2}$. In the finish phase of the fracture (at the same vibration amplitude, but for crack position no 10), the stress intensity factor is about $25 \mathrm{MPa} \cdot \mathrm{m}^{1 / 2}$. When the blade is vibrated with amplitude of $4 \mathrm{~mm}$, the K-factor is about $96 \mathrm{MPa} \cdot \mathrm{m}^{1 / 2}$ in the final phase of the fracture.

Table 1. Values of the geometrical parameters and the auxiliary factors used in Raju-Newman solution for the different crack size

\begin{tabular}{|c|c|c|c|c|c|c|c|c|c|c|c|c|c|c|c|}
\hline $\begin{array}{c}\text { Crack } \\
\text { no. }\end{array}$ & $\begin{array}{c}\mathbf{a} \\
{[\mathbf{m m}]}\end{array}$ & $\begin{array}{c}\mathbf{2 c} \\
{[\mathbf{m m}]}\end{array}$ & $\mathbf{a} / \mathbf{c}$ & $\mathbf{a} / \mathbf{t}$ & $\mathbf{c} / \mathbf{w}$ & $\mathbf{Q}$ & $\mathbf{M}_{\mathbf{1}}$ & $\mathbf{M}_{\mathbf{2}}$ & $\mathbf{M}_{\mathbf{3}}$ & $\mathbf{p}$ & $\mathbf{G}_{\mathbf{1}}$ & $\mathbf{G}_{\mathbf{2}}$ & $\mathbf{I}_{\mathbf{1}}$ & $\mathbf{I}_{\mathbf{2}}$ & $\mathbf{f}_{\mathbf{w}}$ \\
\hline $\mathbf{1}$ & 0,600 & 1,300 & 0,923 & 0,337 & 0,063 & 2,283 & 1,047 & 0,252 & $-0,136$ & 1,325 & $-1,331$ & $-0,022$ & 0,851 & 0,549 & 0,764 \\
\hline $\mathbf{2}$ & 0,860 & 2,500 & 0,688 & 0,483 & 0,122 & 1,790 & 1,068 & 0,462 & $-0,247$ & 1,178 & $-1,303$ & 0,025 & 0,799 & 0,377 & 0,841 \\
\hline $\mathbf{3}$ & 1,070 & 3,800 & 0,563 & 0,601 & 0,186 & 1,568 & 1,079 & 0,626 & $-0,324$ & 1,124 & $-1,288$ & 0,066 & 0,758 & 0,250 & 0,900 \\
\hline $\mathbf{4}$ & 1,220 & 5,000 & 0,488 & 0,685 & 0,244 & 1,448 & 1,086 & 0,754 & $-0,379$ & 1,099 & $-1,279$ & 0,097 & 0,730 & 0,169 & 0,945 \\
\hline $\mathbf{5}$ & 1,400 & 7,000 & 0,400 & 0,787 & 0,342 & 1,323 & 1,094 & 0,943 & $-0,452$ & 1,072 & $-1,268$ & 0,141 & 0,698 & 0,090 & 1,016 \\
\hline $\mathbf{6}$ & 1,470 & 8,000 & 0,368 & 0,826 & 0,391 & 1,281 & 1,097 & 1,028 & $-0,483$ & 1,063 & $-1,264$ & 0,159 & 0,686 & 0,065 & 1,054 \\
\hline $\mathbf{7}$ & 1,540 & 9,000 & 0,342 & 0,865 & 0,439 & 1,250 & 1,099 & 1,101 & $-0,507$ & 1,061 & $-1,261$ & 0,174 & 0,673 & 0,039 & 1,098 \\
\hline $\mathbf{8}$ & 1,590 & 10,000 & 0,318 & 0,893 & 0,488 & 1,221 & 1,101 & 1,178 & $-0,532$ & 1,054 & $-1,258$ & 0,190 & 0,665 & 0,027 & 1,146 \\
\hline $\mathbf{9}$ & 1,710 & 13,000 & 0,263 & 0,961 & 0,635 & 1,162 & 1,106 & 1,382 & $-0,586$ & 1,039 & $-1,252$ & 0,228 & 0,646 & 0,008 & 1,343 \\
\hline $\mathbf{1 0}$ & 1,780 & 17,000 & 0,209 & 1,000 & 0,830 & 1,111 & 1,111 & 1,634 & $-0,614$ & 1,009 & $-1,245$ & 0,270 & 0,637 & 0,025 & 1,945 \\
\hline
\end{tabular}


Table 2. Values of the $f_{\phi} g, F, H$ parameters and stress intensity factor values for the blade vibrated with different amplitude

\begin{tabular}{|c|c|c|c|c|c|c|c|c|}
\hline $\begin{array}{c}\text { Crack } \\
\text { no. }\end{array}$ & $\mathbf{f} \phi(\phi=0)$ & $\mathbf{g}(\phi=0)$ & $\mathbf{F}$ & $\mathbf{H}(\phi=0)$ & $\begin{array}{c}\mathbf{K}_{\mathbf{I}}(\phi=0) \\
(\mathrm{A}=1 \mathrm{~mm}) \\
\mathbf{M p a}^{\mathbf{x}} \mathbf{m}^{1 / 2}\end{array}$ & $\begin{array}{c}\mathbf{K}_{\mathrm{I}}(\phi=0) \\
(\mathrm{A}=2 \mathrm{~mm}) \\
\mathbf{M p a}^{\mathbf{X}} \mathbf{m}^{\mathbf{1} 2}\end{array}$ & $\begin{array}{c}\mathbf{K}_{\mathrm{I}}(\phi=0) \\
(\mathrm{A}=3 \mathrm{~mm}) \\
\mathbf{M p a}^{\mathbf{x}} \mathbf{m}^{1 / 2}\end{array}$ & $\begin{array}{c}\mathbf{K}_{\mathrm{I}}(\phi=0) \\
(\mathrm{A}=4 \mathrm{~mm}) \\
\mathbf{M p a}^{\mathbf{x}} \mathbf{m}^{1 / 2}\end{array}$ \\
\hline 1 & 0,961 & 1,140 & 0,898 & 0,851 & 4,264 & 8,528 & 12,792 & 17,056 \\
\hline 2 & 0,829 & 1,182 & 0,959 & 0,799 & 5,778 & 11,556 & 17,334 & 23,112 \\
\hline 3 & 0,750 & 1,226 & 1,046 & 0,758 & 7,130 & 14,260 & 21,390 & 28,520 \\
\hline 4 & 0,699 & 1,264 & 1,132 & 0,730 & 8,254 & 16,507 & 24,761 & 33,015 \\
\hline 5 & 0,632 & 1,317 & 1,272 & 0,698 & 9,940 & 19,880 & 29,820 & 39,761 \\
\hline 6 & 0,606 & 1,339 & 1,346 & 0,686 & 10,762 & 21,524 & 32,286 & 43,048 \\
\hline 7 & 0,585 & 1,362 & 1,434 & 0,673 & 11,664 & 23,328 & 34,991 & 46,655 \\
\hline 8 & 0,564 & 1,379 & 1,517 & 0,665 & 12,526 & 25,053 & 37,579 & 50,105 \\
\hline 9 & 0,513 & 1,423 & 1,846 & 0,646 & 15,727 & 31,455 & 47,182 & 62,910 \\
\hline 10 & 0,458 & 1,450 & 2,750 & 0,637 & 24,122 & 48,245 & 72,367 & 96,489 \\
\hline
\end{tabular}

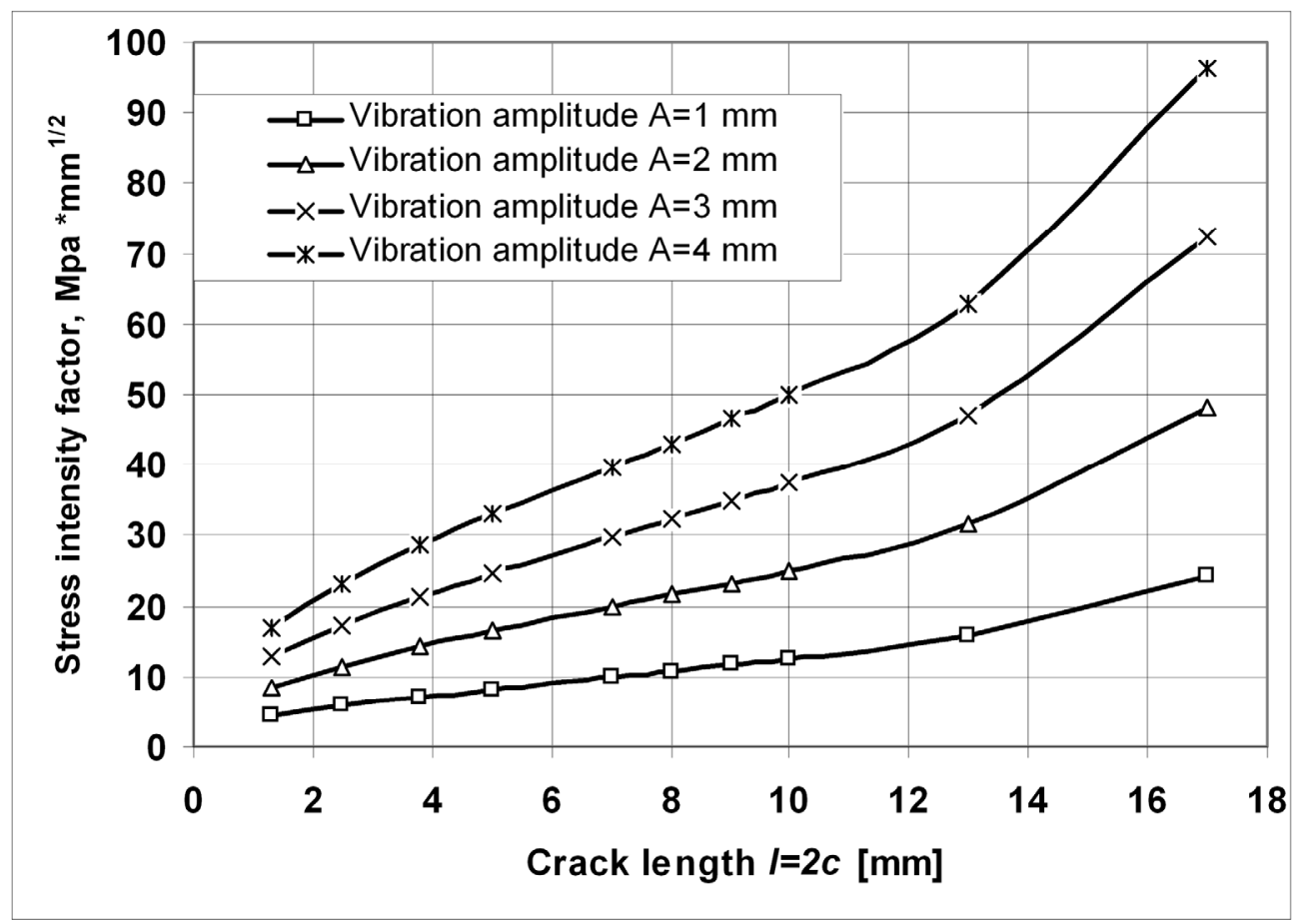

Fig. 7. Value of the stress intensity factors (for direction $\phi=0$ ) for different blade vibration amplitude

\section{CRACK GROWTH ANALYSIS}

The stress intensity factor is the main parameter during an analytical or numerical crack growth analysis. According to the Paris-Erdogan equation $[8,9]$, the crack growth rate can be computed from the following formula:

$$
\frac{d l}{d N}=C \cdot(\Delta K)^{m}
$$

where:

$\mathrm{dl} / \mathrm{dN}$ - the crack growth rate (growth of the crack after one fatigue cycle);

$\mathrm{C}, \mathrm{m}$ - the Paris constants 
Value of $\Delta \mathrm{K}$ is computed from equation:

$$
\Delta K=K_{\max }-K_{\min }
$$

where:

$\mathrm{K}_{\max }$ - maximum value of $\mathrm{K}$-factor in one fatigue cycle,

$\mathrm{K}_{\min }$ - minimum value of $\mathrm{K}$-factor in the fatigue cycle.

In the presented analysis, the following material constants for the EI-961 alloy were defined: $\mathrm{C}=1,27 \times 10^{-11} \mathrm{~m} /$ cycle and $\mathrm{m}=3[8,9]$.

The $\mathrm{dl}$ and $\mathrm{dN}$ parameters in the Paris-Erdogan solution can be written in the finite (increment) form:

$$
\frac{\Delta l}{\Delta N}=C \cdot(\Delta K)^{m}
$$

where:

$\Delta \mathrm{l}=\mathrm{l}_{2}-\mathrm{l}_{1}$

$1_{2}, 1_{1}$ the cracks length between adjacent increments

$\Delta \mathrm{N}$ - number of cycles which is needed for growth of the crack from size $l_{1}$ to $l_{2}$

After transformation of equation (18), the partial number of cycles $\Delta \mathrm{N}$ for growth of the crack from size $l_{1}$ to $l_{2}$ can be expressed as follows:

$$
\Delta N=\frac{\Delta l}{C \cdot(\Delta K)^{m}}
$$

The total number of cycles is computed by summing the partial $(\Delta \mathrm{N})$ numbers of cycles:

$$
N=\sum_{i=1}^{n} \Delta N
$$

where: $\mathrm{n}$ - number of increment (crack number in Tab. 3)

The values of the partial $(\Delta \mathrm{N})$ and total $(\mathrm{N})$ number of fatigue cycles for the blade vibrating at different amplitudes are shown in Tab. 3. The $\Delta \mathrm{N}$ and $\mathrm{N}$ values were computed using equations (19) and (20).

Table 3. Values of the partial $(\Delta N)$ and total $(N)$ number of fatigue cycles for the blade vibrating at different amplitudes

\begin{tabular}{|c|c|c|c|c|c|c|c|c|c|c|c|}
\hline Crack & $\mathrm{a}$ & $\mathrm{l}=2 \mathrm{c}$ & $\Delta \mathrm{l}$ & $\Delta \mathrm{N}$ & $\mathrm{N}$ & $\Delta \mathrm{N}$ & $\mathrm{N}$ & $\Delta \mathrm{N}$ & $\mathrm{N}$ & $\Delta \mathrm{N}$ & $\mathrm{N}$ \\
\hline no. & {$[\mathrm{mm}]$} & {$[\mathrm{mm}]$} & {$[\mathrm{mm}]$} & $\begin{array}{c}\text { for } \\
\mathrm{A}=1 \mathrm{~mm}\end{array}$ & $\begin{array}{c}\text { for } \\
\mathrm{A}=1 \mathrm{~mm}\end{array}$ & $\begin{array}{c}\text { for } \\
\mathrm{A}=2 \mathrm{~mm}\end{array}$ & $\begin{array}{c}\text { for } \\
\mathrm{A}=2 \mathrm{~mm}\end{array}$ & $\begin{array}{c}\text { for } \\
\mathrm{A}=3 \mathrm{~mm}\end{array}$ & $\begin{array}{c}\text { for } \\
\mathrm{A}=3 \mathrm{~mm}\end{array}$ & $\begin{array}{c}\text { for } \\
\mathrm{A}=4 \mathrm{~mm}\end{array}$ & $\begin{array}{c}\text { for } \\
\mathrm{A}=4 \mathrm{~mm}\end{array}$ \\
\hline & & & & $\begin{array}{c}\text { Partial no. } \\
\text { of cycles }\end{array}$ & $\begin{array}{c}\text { Total no. of } \\
\text { cycles }\end{array}$ & $\begin{array}{c}\text { Partial no. } \\
\text { of cycles }\end{array}$ & $\begin{array}{c}\text { Total no of } \\
\text { cycles }\end{array}$ & $\begin{array}{c}\text { Partial no. } \\
\text { of cycles }\end{array}$ & $\begin{array}{c}\text { Total no. } \\
\text { of cycles }\end{array}$ & $\begin{array}{c}\text { Partial no. } \\
\text { of cycles }\end{array}$ & $\begin{array}{c}\text { Total no. } \\
\text { of cycles }\end{array}$ \\
\hline 1 & 0,60 & 1,3 & 1,3 & 1320289 & 1320289 & 165036 & 165036 & 48900 & 48900 & 20630 & 20630 \\
\hline 2 & 0,86 & 2,5 & 1,2 & 489816 & 1810104 & 61227 & 226263 & 18141 & 67041 & 7653 & 28283 \\
\hline 3 & 1,07 & 3,8 & 1,3 & 282415 & 2092519 & 35302 & 261565 & 10460 & 77501 & 4413 & 32696 \\
\hline 4 & 1,22 & 5,0 & 1,2 & 168050 & 2260569 & 21006 & 282571 & 6224 & 83725 & 2626 & 35321 \\
\hline 5 & 1,40 & 7,0 & 2,0 & 160342 & 2420911 & 20043 & 302614 & 5939 & 89663 & 2505 & 37827 \\
\hline 6 & 1,47 & 8,0 & 1,0 & 63169 & 2484080 & 7896 & 310510 & 2340 & 92003 & 987 & 38814 \\
\hline 7 & 1,54 & 9,0 & 1,0 & 49623 & 2533703 & 6203 & 316713 & 1838 & 93841 & 775 & 39589 \\
\hline 8 & 1,59 & 10,0 & 1,0 & 40061 & 2573764 & 5008 & 321720 & 1484 & 95325 & 626 & 40215 \\
\hline 9 & 1,71 & 13,0 & 3,0 & 60722 & 2634486 & 7590 & 329311 & 2249 & 97574 & 949 & 41164 \\
\hline 10 & 1,78 & 17,0 & 4,0 & 22439 & 2656925 & 2805 & 332116 & 831 & 98405 & 351 & 41514 \\
\hline
\end{tabular}


The crack growth rate for different amplitudes of vibration, computed according to formula (20) is presented in Fig. 8. In order to improve the visibility of the obtained results, the crack growth plots begin from the increment defined for the crack length equal 1,3 $\mathrm{mm}$ (crack length range of $0-1,3 \mathrm{~mm}$ was neglected in the plots).

Figure 8 shows that the blade vibrating at constant amplitude of $4 \mathrm{~mm}$ needs about $2,2 \times 10^{4}$ cycles to grow from size $1=1,3 \mathrm{~mm}$ to $17 \mathrm{~mm}$. In the first phase of fatigue (first 10000 cycles), the crack propagates relatively slowly. After about $1 \times 10^{4}$ cycles, the accelerated crack growth is observed. When the vibration amplitude is smaller (i.e. $2 \mathrm{~mm}$ ), the crack propagation process is considerably longer $\left(1,67 \times 10^{5}\right.$ cycles $)$.

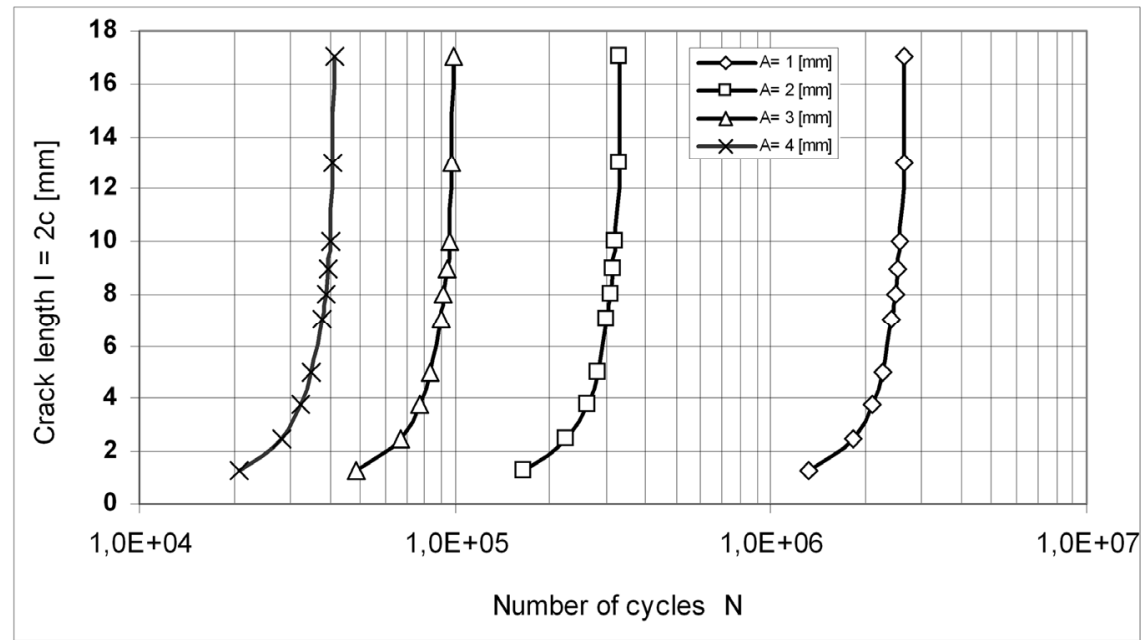

Fig. 8. Crack growth rate computed based on the Paris equation for crack tip position $\phi=0$ and for different vibration amplitudes

In Fig. 9 the comparison between the numerical and experimental crack growth rate for the compressor blade is presented. The experimental crack growth curve was obtained in the test, in which the intensity of vibration (excitation) equaled $7 \mathrm{~g}$. For this excitation intensity, the blade tip amplitude of $2 \mathrm{~mm}$ was observed. The blade during experimental investigations was gradually damaged. During cracking, the bending stiffness of the blade decreased. As a result, the resonant frequency of the blade also decreased. In order to maintain the constant blade amplitude during the fatigue test, the excitation frequency and the vibration intensity were changed.

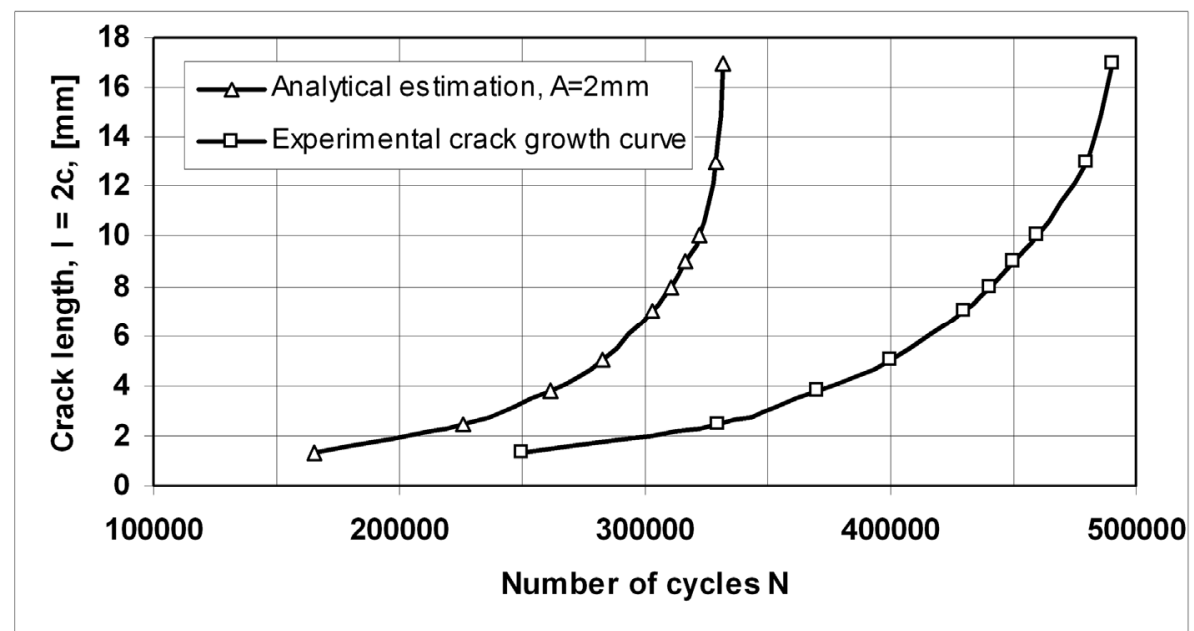

Fig. 9. Comparison of the numerical and experimental crack growth rates for the compressor blade vibrating with amplitude of $2 \mathrm{~mm}$ 
As seen in Fig. 9, the crack in the blade achieved length of $4 \mathrm{~mm}$ after about $2,6 \times 10^{5}$ cycles (computed based on the Raju-Newman and Paris solutions). During the experimental fatigue test, the $4 \mathrm{~mm}$ crack was detected after about $3,7 \times 10^{5}$ cycles. Thus, the difference between the numerical and experimental results is about $1,1 \times 10^{5}$ cycles. It gives the relative error of about $30 \%$. For the crack size of $10 \mathrm{~mm}$, the experimental curve has a lower slope than the analytical one, and, in consequence, the error at this stage of fracture is slightly bigger $(33 \%)$. In the final phase of fracture (for $1=17 \mathrm{~mm}$ ), the number of cycles estimated in the analytical way is about 3,8 $\times 10^{5}$, while the experimental result is $4,9 \times 10^{5}$ cycles.

In the comparison described below, the partial number of cycles computed from the Paris equation in the first increment $(0-1,3 \mathrm{~mm})$ was also included. However, the consideration of this increment in the comparison of analytical and experimental results is controversial because the Paris equation describes correctly only the stable phase of the crack growth. After the omission of the first increment, the difference between the analytical and numerical solution is much smaller.

\section{CONCLUSIONS}

In this study, the stress intensity factor for the 1st stage compressor blade was computed. In this analysis, the Raju-Newman analytical solution was used. A half-elliptical surface crack was embedded in the analyzed blade. The location of this crack and the crack front shape were defined based on the experimental results obtained for the blade tested in resonance conditions. The Kfactor values were computed only at one point of the crack front, where the crack tip touches the free surface as the crack length (1) was measured just in this direction $(\phi=0)$ during experimental investigations. In order to determine the stress intensity factors for different crack sizes, ten diverse flaws in the blade were defined.

In the next part of this work, the stress intensity factor values were used as an input data into the Paris-Erdogan equation. As a result of this calculation, the crack growth rate for the compressor blade vibrating at constant amplitude was estimated. The obtained results were finally compared with the results of the experimental crack growth analysis performed for 1st stage compressor blades of the helicopter turbo-engine.

The results obtained in the analytical way are conservative (from the engineering point of view). The analytical estimation using the Raju-Newman and Paris equations gives the fatigue cycle values which are about 30\% lower than those obtained in the experimental tests. This divergence could be caused by inaccurate definitions of $\mathrm{C}$ and $\mathrm{m}$ constants in the Paris equation. Moreover, the replacement of the real blade cross-section with the rectangular shape has a certain influence on the accuracy of the analytical solution. After the omission of the first increment (concerning crack growth from initiation to length $1=1,3 \mathrm{~mm}$ ), the difference between the analytical and numerical solution is much smaller.

The author's intention is to calculate (in the next study) the stress intensity factor in the compressor blade using the hybrid method. In this approach, the finite element method will be used for stress analysis. Subsequently, the boundary element method will be utilized for the crack definition and also for the stress intensity factor calculation. The obtained numerical results can be compared with the K-factor values computed from the Raju-Newman solution.

\section{ACKNOWLEDGEMENT}

This work was supported by the Polish Ministry of Science and Higher Education (Project No. N N - 504 346736). 


\section{REFERENCES}

[1] Newman, J.C. Jr. \& Raju, I.S. (1981). An empirical stress intensity factor equation for surface cracks. Engineering Fracture Mechanics, Vol. 15, pp. 185-192.

[2] Barlow, K.W. \& Chandra, R.(2005). Fatigue crack propagation simulation in an aircraft engine fan blade attachment. International Journal of Fatigue. 27(10-12), 1661-1668.

[3] Poursaeidi, E. \& Salavatian, M. (2009). Fatigue crack growth simulation in a generator fan blade. Engineering Failure Analysis. 16(3), 888-898.

[4] Nikhamkin, N. (1996). Crack propagation in turbojet blades. Experimental technique and results. International Journal of Fatigue. 18(8), pp. 604.

[5] Troshchenko, V.T. \& Prokopenko, A.V. (2000). Fatigue strength of gas turbine compressor blades. Engineering Failure Analysis. 7(3), 209-220.

[6] Witek, L. (2010). Modelowanie procesu zmęczeniowego pękania turbiny silnika przepływowego. Journal of Aeronautica Integra. (2)2010.

[7] Witek, L. (2009). Experimental crack propagation and failure analysis of the first stage compressor blade subjected to vibration. Engineering Failure Analysis. 16(7), 2163-2170.

[8] Anderson T. L. (1991). Fracture mechanics - Fundamentals and applications. CRC Press Inc., 2000 Corporate Blvd. Boca Raton, Florida.

[9] Neimitz A. (1998). Fracture Mechanics. Warszawa: PWN. 